\title{
The Essential Oil Content and Composition of Selected Salvia Species, Sage Teas, and Sage Drops
}

\author{
Stefanie Oelschlägel, Sabine Quaas and Karl Speer \\ Food Chemistry, Technical University Dresden, Dresden, Saxony 01069, Germany
}

Received: May 11, 2012 / Published: August 20, 2012.

\begin{abstract}
Sage is popular for its manifold applications and has always been used in herbalism. The Salvia genus encompasses up to 900 species, but only a few of them have been investigated. Hence, the objective was to investigate the essential oil content as well as the terpene composition of a number of Saliva species. In this context, S. officinalis var. Extrakta, S. officinalis "Aurea" and S. patens were investigated for the first time. To some extent, it was also possible to associate the terpene distribution of the investigated commercial sage teas and drops with the processed sage oil. Furthermore, an ultrasonic extraction with ethyl acetate seems to be an efficient quick-method for extracting the essential oil.
\end{abstract}

Key words: Essential oil, Salvia officinalis, sage tea, sage drops, thujone.

\section{Introduction}

Saliva officinalis (common sage) is a versatile plant. In cooking, it is used especially as an aromatic herbal seasoning. However, above all, it is part of herbalism. Due to its antioxidant, antibacterial, antifungal, and anti-inflammatory properties sage extracts or tinctures are applied orally or dermally [1-4]. For instance, besides its main use as a tea, sage is also processed into drops for alleviating oropharyngeal inflammations. Here, the polyphenols, but also the terpenes, contained in the essential oil are responsible for the characteristic flavour as well as the antibacterial effect of the herb.

Due to its robustness especially garden sage (Salvia officinalis) is cultivated in Central Europe. Additionally, the essential oils of Spanish sage (Salvia lavandulifolia) and clary sage (Salvia sclarea) are used in the pharmaceutical as well as the perfume industry [5, 6]. Overall, there are about 900 species of sage (Lamiaceae) known [7], although they have hardly been investigated. Therefore, one objective was

Corresponding author: Karl Speer, professor, research fields: secondary plant products in coffee, tea, honey, plants. E-mail: karl.speer@chemie.tu-dresden.de. to examine the essential oil of 15 different sage species or subspecies, including commercially relevant as well as ornamental species. Their characteristic differences concerning the essential oil yields and the terpene composition were to be emphasized. On the basis of the terpene composition it was also to be determined which sage species had possibly been used for the sage teas and the production of the sage drops. In addition, with regard to the thujone enclosed in the essential oil, the toxicologically relevant $\alpha$-thujone yields of the commercially used Salvia species, the teas, and the drops were compared.

Since there are various methods reported in the literature for the extraction of the essential oil, a comparison of selected distillation techniques was accomplished. Even though the extraction of the sage oil by means of supercritical $\mathrm{CO}_{2}$ [8], SPME (Solid-Phase Micro-extraction), and SDME (Single-Drop Micro-extraction) in combination with a headspace analysis [9] as well as MSPD (Matrix Solid-Phase Dispersion) [10] have been described in literature, steam distillation was the most common method used [11-14]. Steam distillation with simultaneous extraction and 
distillation can be divided up between apparatuses with a scale, such as the Moritz-Apparatus, and apparatuses without this option such as the Clevenger-Extraction and the Micro-Distiller. Since all steam distillation methods are applied for high sample weights between $10 \mathrm{~g}$ and $20 \mathrm{~g}$, a further objective was to prove their capability for lower sample weights up to $3.0 \mathrm{~g}$, especially with regard to commercially available pre-packaged sage teas or drops.

\section{Materials and Methods}

\subsection{Plant Material, Sage Tea \& Drops}

Fresh leaves of 15 different sage species and subspecies (S. coccinea, S. farinacea, S. patens, S. splendens, S. barrelieri, S. lavandulifolia, S. madrensis, S. sclarea var. turkestanica, S. officinalis, S. officinalis ssp. major, S. officinalis ssp. minor "Alba", S. officinalis var. Extrakta, S. officinalis "Aurea”, S. officinalis "Berggarten", S. elegans "Scarlet Pineapple") were examined. The essential oil yields were determined in the dry matter obtained from $3 \mathrm{~g}$ of fresh leaves, respectively. For this, the fresh leaves (including leafstalks) were dried at $40{ }^{\circ} \mathrm{C}$, and subsequently, finely ground to improve homogeneity. In addition, five commercially available sage teas and six kinds of sage drops from the German market were analysed with regard to their essential oil composition. The teas were treated just like the dried leaves, and for the determination of the essential oil content in the sage drops, $3 \mathrm{~g}$ of the ground sample were extracted. All analyses were carried out in duplicate.

\subsection{Gas Chromatography}

The quantification of the terpenes was performed by employing the GC-FID system (Hewlett Packard HP6890, Agilent). The compounds were separated on a DB-5 capillary column $(30 \mathrm{~m} \times 0.25 \mathrm{~mm}, 0.25 \mu \mathrm{m}$ film thickness; Hewlett Packard HP19091S-433), injecting $1 \mu \mathrm{L}$, respectively. Nitrogen was used as carrier gas at a flow rate of $0.7 \mathrm{~mL} \mathrm{~min}^{-1}$. The column temperature was initially set at $50{ }^{\circ} \mathrm{C}$. The temperature gradient consisted of six heating stages: $10^{\circ} \mathrm{C} \mathrm{min}^{-1}$ to $65^{\circ} \mathrm{C}, 1{ }^{\circ} \mathrm{C} \min ^{-1}$ to $75{ }^{\circ} \mathrm{C}, 10{ }^{\circ} \mathrm{C} \min ^{-1}$ to $100{ }^{\circ} \mathrm{C}$, $8{ }^{\circ} \mathrm{C} \min ^{-1}$ to $200{ }^{\circ} \mathrm{C}$, and, finally, $50{ }^{\circ} \mathrm{C} \min ^{-1}$ to $300{ }^{\circ} \mathrm{C}$. The temperature of the detector was set at $280{ }^{\circ} \mathrm{C}$. The identification of the terpenes was carried out by GC-MS via the NIST database and reference substances. Thereby, the retention indices could not be determined since the separation was not accomplished under isothermal conditions. For the identification, a Thermo Scientific Trace GC Ultra in combination with a CTC Combi PAL autosampler was used. The column as well as the temperature program remained the same. The detection was carried out by means of a DSQ II (EI, 70eV) in the mass range from 45 to $300 \mathrm{~m}$ $\mathrm{z}^{-1}$. The injection mode was split $(1: 10)$ and the MS interface temperature was set at $250{ }^{\circ} \mathrm{C}$. Pelargonic acid methyl ester (Fluka, Sigma-Aldrich Chemie, Taufkirchen, Germany) which was added after the extraction was used as internal standard and for the estimation of the terpene yields. The linearity range was determined from 3 to $780 \mu \mathrm{g} \mathrm{mL}^{-1}$ and recovery resulted in $97 \%$.

\subsection{Steam Distillation}

\subsubsection{Moritz-Apparatus (MA)}

The dried plant material was mixed with $250 \mathrm{~mL}$ bi-distilled water and distilled for $2 \mathrm{~h}$ [15]. The scale (0.3:0.001 mL) displayed the volume of the obtained essential oil (Fig. 1). Subsequently, the essential oil was dissolved in $10 \mathrm{~mL}$ anhydrous ethyl acetate for GC analysis. The reproducibility was determined to $2.5 \%$ and the repeatability to $14.6 \%$.

\subsubsection{Clevenger-Extraction (CE)}

Based on the method by Langa et al. [13], the dried plant material was distilled with $150 \mathrm{~mL}$ bi-distilled water for $4 \mathrm{~h}$ and $5 \mathrm{~mL}$ ethyl acetate located in the branch of the apparatus (Fig. 1) served as extracting agent. The essential oil extract was dried over anhydrous sodium sulphate, and the final volume was adjusted to $10 \mathrm{~mL}$ with ethyl acetate. The reproducibility was determined to $0.5 \%$ and the repeatability to $4.1 \%$. 


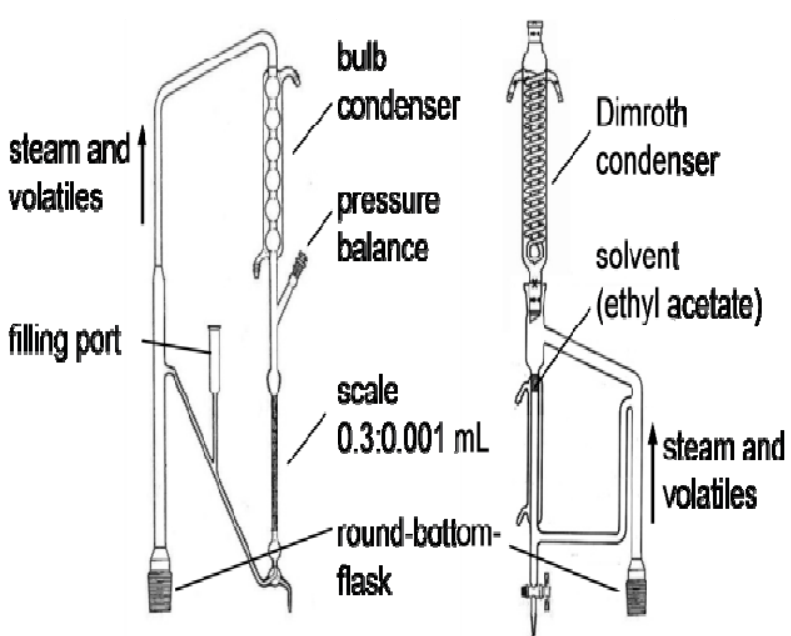

Fig. 1 Moritz-Apparatus (left) based on the European pharmacopoeia [15], Clevenger-Apparatus (right).

\subsection{Ultrasonic Extraction (USE)}

The dried plant material was mixed with $10.0 \mathrm{~mL}$ ethylacetate and the screw-top test tube was placed in an ultrasonic bath for $20 \mathrm{~min}$ at $25^{\circ} \mathrm{C}$. After filtration ( $0.2 \mu \mathrm{m}$ pore size, Sartorius), the extract was analysed by gas chromatography. The reproducibility was determined to $0.5 \%$ and the repeatability to $4.7 \%$.

\section{Results and Discussion}

\subsection{Extraction of the Essential Oil}

MA is used in food control and pharmacognosy for the determination of the essential oil yield in spices and drugs [16]. The method is described for sample weights of $20 \mathrm{~g}$ drug and an apparatus with a scale of 1.0:0.01 mL filled with $0.5 \mathrm{~mL}$ xylene as a keeper. Since the sample amount per plant was limited, an apparatus with a narrow scale $(0.3: 0.003 \mathrm{~mL})$ without xylene was applied. Hence, the verification of the method was necessary. The comparison of different extraction times (Fig. 2) as well as the determined correlation $\left(\mathrm{R}^{2}=0.998\right)$ of the sample weight to the essential oil volume of S. officinalis var. Extrakta (Fig. 3) proved the accuracy of the method at the defined extraction time of $2 \mathrm{~h}$.

With regard to the CE, different extraction times are described for sage oil $[12,13,17,18]$. However, according to the total peak area of the terpenes

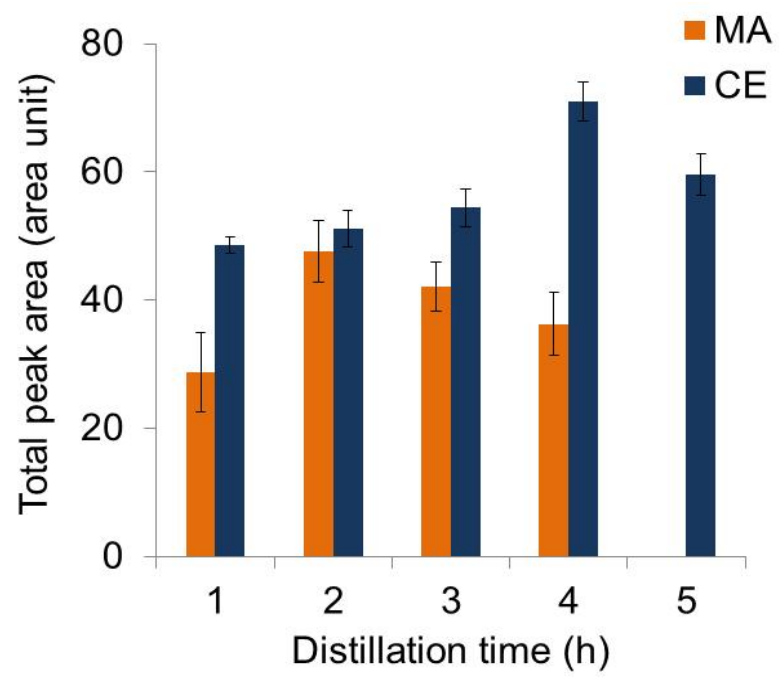

Fig. 2 Impact of the extraction time on the terpene content of $1.4 \mathrm{~g}$ S. officinalis var. Extrakta, Moritz-Apparatus (MA), Clevenger-Extraction (CE) (mean \pm SD).

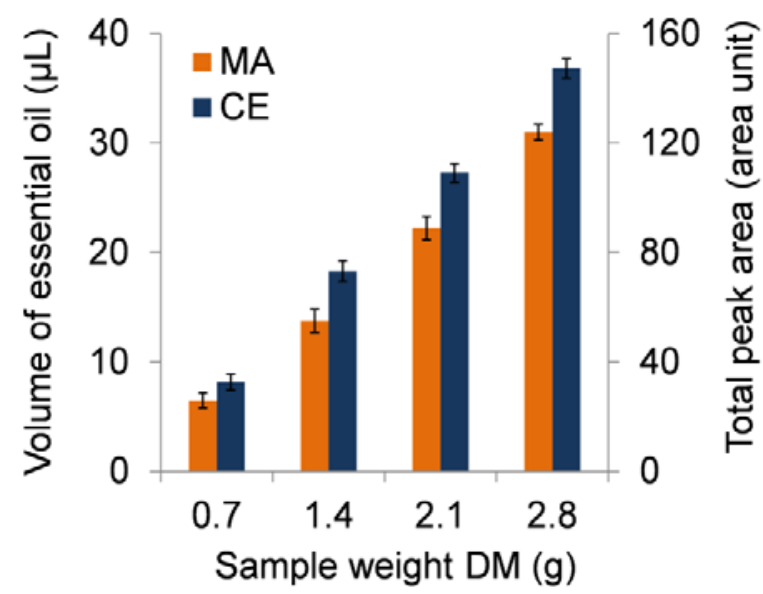

Fig. 3 Linear correlation of the sample weight ( $S$. officinalis var. Extrakta) and the essential oil volume (MA, $2 \mathrm{~h}$ extraction) or the terpene content (CE, $4 \mathrm{~h}$ extraction); DM dry matter (mean \pm SD).

depending on the extraction time, it was observed that $4 \mathrm{~h}$ of distillation were necessary for a complete extraction (Fig. 2). The correlation of the sample weight ( 0.7 to $2.8 \mathrm{~g}$ dry matter) to the terpene content resulted in $\mathrm{R}^{2}=0.999$.

To compare both extraction techniques (MA $2 \mathrm{~h}$ vs. CE $4 \mathrm{~h}$ ), the total terpene contents of the dried $S$. officinalis var. Extrakta leaves were compared (Fig. 2, Table 1). For this, the CE seemed to be more efficient; the essential oil yields increased by about $40 \%$. This discrepancy was caused by the MA being more difficult to handle as well as to incipient evaporation 
Table 1 Comparing the essential oil yields extracted with Moritz-Apparatus (MA), Clevenger-Extraction (CE) and ultrasonic extraction (USE).

\begin{tabular}{|c|c|c|c|c|}
\hline \multirow[t]{2}{*}{ Sample } & \multirow{2}{*}{$\begin{array}{l}\text { Sample } \\
\text { weight } \\
\text { (g DM) }\end{array}$} & \multicolumn{3}{|c|}{$\begin{array}{l}\text { Essential oil yield } \\
\left(\mathrm{mL} 100^{-1} \mathrm{~g}^{-1} \mathrm{DM}\right)\end{array}$} \\
\hline & & $\mathrm{MA}$ & $\mathrm{CE}^{1}$ & $\mathrm{USE}^{1}$ \\
\hline \multirow{4}{*}{$\begin{array}{l}\text { S. officinalis } \\
\text { var. Extrakta }\end{array}$} & 0.7 & 0.9 & 1.7 & 1.9 \\
\hline & 1.4 & 1.0 & 1.8 & 2.1 \\
\hline & 2.8 & 1.0 & 1.8 & 2.0 \\
\hline & 4.2 & 1.1 & 1.7 & 2.0 \\
\hline Tea 1 & 1.4 & 1.1 & 1.8 & 2.0 \\
\hline Tea 4 & 1.4 & 1.3 & 2.2 & 2.6 \\
\hline Tea 5 & 1.4 & 1.2 & 2.0 & 2.4 \\
\hline
\end{tabular}

Calculated oil contents according to the formula (Fig. 4), DM dry matter.

with an increase in the MA distillation time. While the essential oil extracted via Clevenger was enriched in an ethyl acetate phase, being easily accessible through a valve, the essential oil of the MA was subsequently collected by rinsing with ethyl acetate. The advantage of the MA, on the other hand, is the direct determination of the essential oil volume with the implemented scale. To be able to specify the essential oil content as well as the terpene composition, it would have been preferable to apply both methods. However, the available sample amounts were insufficient for executing both extractions as duplicates. Since the analyte discrimination was lower when using the CE, the oil volume had to be determined indirectly according to the total terpene content. Therefore, the ratio of the extracted essential oil and the total terpene content obtained after MA extraction was assumed to be constant and could, thus, be expressed as a factor (Fig. 4, Eq. 1). Since this ratio was to be the same for the $\mathrm{CE}$ too, the factor calculated for MA could be used to determine the essential oil volume according to the total peak area after CE (Eq. 2). After considering the applied sample weight, the essential oil yield could be expressed in millilitre per 100 gram $\left(\mathrm{mL} 100^{-1} \mathrm{~g}^{-1}\right)$ dry matter (Eq. 3).

It was further examined whether decomposition reactions took place in the Clevenger-Apparatus at $100{ }^{\circ} \mathrm{C}$ during the $4 \mathrm{~h}$ extraction. Therefore, USE with ethyl acetate as extracting agent was applied. As the

$$
\begin{aligned}
& F_{M A}=\frac{A_{M A}}{V_{M A}}(1) \\
& V_{C E}-\frac{A_{C E}}{F_{M A}}(2) \\
& w_{C E}\left[\frac{m L}{100 g D M}\right]=\frac{V_{C K} \cdot 100}{E_{C E}}
\end{aligned}
$$

Fig. 4 Equation for the calculation of the essential oil yields after $\mathbf{C E}$.

$F_{M A}$ : factor; $A_{M A / C E}$ : total peak area after MA or CE (area units); $V_{M A}$ : measured volume of essential oil in MA $(\mathrm{mL}) ; V_{C E}$ : calculated volume of essential oil after $\mathrm{CE}(\mathrm{mL}) ; E_{C E}$ : sample weight $(\mathrm{g}) ; w_{C E}$ : essential oil yield after CE $\left(\mathrm{mL} 100^{-1} \mathrm{~g}^{-1} \mathrm{DM}\right)$

terpene profile remained the same in quality as well as in quantity, a thermal degradation was excluded (Fig. 5). Moreover, since the terpene yields and hence the essential oil yields obtained with USE after a 20 min extraction were comparable to those gained with the CE after a $4 \mathrm{~h}$ extraction (Table 1), the USE could be employed as a quick-method.

\subsection{Salvia Species and Subspecies}

The determined oil yields are displayed in Table 2 . Among the $S$. officinalis species, the highest yields were obtained for "Berggarten" sage $(2.6 \%, \mathrm{v} / \mathrm{w})$ and the lowest for "Aurea" $(1.5 \%)$. However, the oil yields of the investigated $S$. officinalis species were not significantly different. Nevertheless, the majority of the non-officinalis species contained significantly less essential oil, except for the Spanish sage (S. lavandulifolia $2.9 \%$ ). Besides the commercially used species, S. barrelieri also revealed a high essential oil content (1.1\%). However, this was about $42 \%$ less than in the analysed S. officinalis subspecies. Within the ornamental species, S. splendens, S. coccinea, and $S$. farinacea showed the lowest oil yields $(0.01 \%-0.05 \%)$. With regard to the literature data, the extracted oil yields were slightly higher (Table 2). This discrepancy was most likely due to varying drying procedures, regional soil conditions such as salt content [14], and climatic differences as well as the point of harvest whereby the oil formation is the 


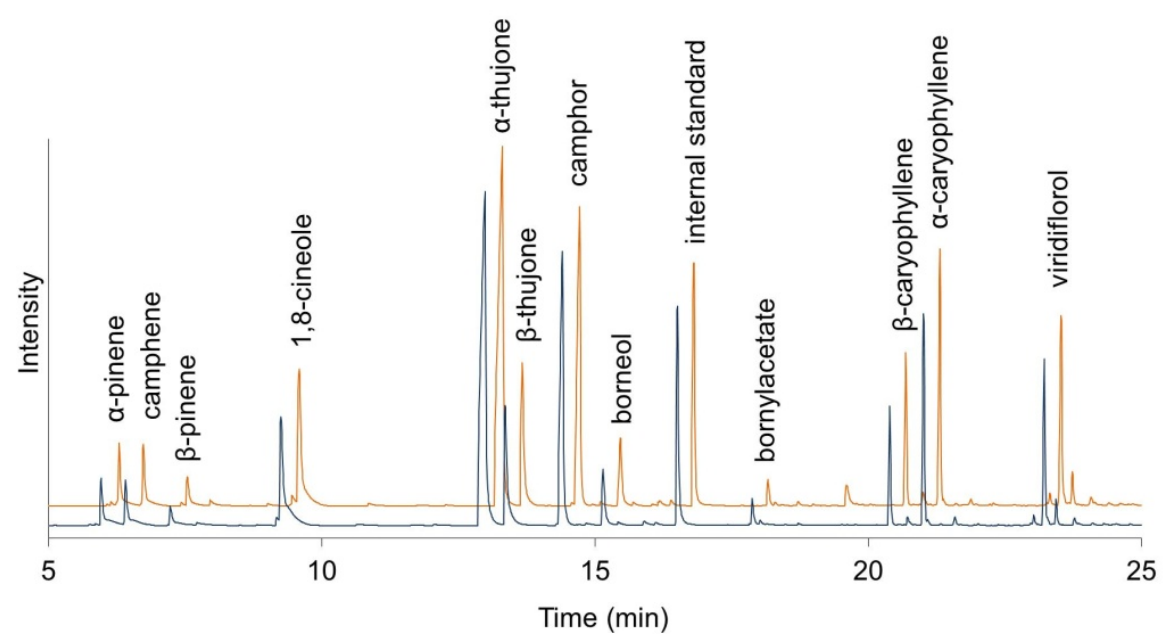

Fig. 5 GC-FID, segment 5 to 25 min, major terpenes of S. officinalis var. Extrakta after CE (bottom) and after USE (top, x-axis off-set).

Table 2 Essential oil yields of different Salvia species, teas, and drops, determined with $\mathrm{CE}$, (comparison to available literature data).

\begin{tabular}{|c|c|c|c|}
\hline \multicolumn{2}{|c|}{ Salvia species } & \multicolumn{2}{|c|}{$\left(\mathrm{mL} 100^{-1} \mathrm{~g}^{-1} \mathrm{DM}\right)$} \\
\hline \multicolumn{2}{|c|}{ S. officinalis } & \multicolumn{2}{|c|}{$1.9(1.1[19], 1.3[20])$} \\
\hline \multicolumn{2}{|c|}{ S. off. ssp. major } & \multicolumn{2}{|c|}{$2.2(1.0[21])$} \\
\hline \multicolumn{2}{|c|}{ S. off. ssp. minor "Alba" } & \multicolumn{2}{|c|}{$1.9(1.6[22])$} \\
\hline \multicolumn{2}{|c|}{ S. off. var. Extrakta } & \multicolumn{2}{|l|}{1.6} \\
\hline \multicolumn{2}{|c|}{ S. off. "Aurea" } & \multicolumn{2}{|l|}{1.5} \\
\hline \multicolumn{2}{|c|}{ S. off. "Berggarten" } & \multicolumn{2}{|l|}{2.6} \\
\hline \multicolumn{2}{|c|}{ S. barrelieri } & \multicolumn{2}{|l|}{1.1} \\
\hline \multicolumn{2}{|c|}{ S. coccinea } & \multicolumn{2}{|l|}{0.03} \\
\hline \multicolumn{2}{|c|}{ S. elegans } & \multicolumn{2}{|c|}{$0.3(0.6[23])$} \\
\hline \multicolumn{2}{|c|}{ S. farinacea } & \multicolumn{2}{|l|}{0.01} \\
\hline \multicolumn{2}{|c|}{ S. lavandulifolia } & \multicolumn{2}{|c|}{$2.9(1.9[13])$} \\
\hline \multicolumn{2}{|c|}{ S. madrensis } & \multicolumn{2}{|c|}{1.1} \\
\hline \multicolumn{2}{|l|}{ S. patens } & \multicolumn{2}{|l|}{0.3} \\
\hline \multicolumn{2}{|c|}{ S. sclarea } & \multicolumn{2}{|c|}{$0.5(0.3[24], 0.5[25])$} \\
\hline \multicolumn{2}{|c|}{ S. splendens } & \multicolumn{2}{|l|}{0.1} \\
\hline \multicolumn{2}{|c|}{$\begin{array}{l}\text { Sage drops } \\
\left(\mathrm{mL} 100^{-1} \mathrm{~g}^{-1}\right)\end{array}$} & \multicolumn{2}{|c|}{$\begin{array}{l}\text { Sage teas } \\
\left(\mathrm{mL} 100^{-1} \mathrm{~g}^{-1} \mathrm{DM}\right)\end{array}$} \\
\hline Drops 1 & 0.01 & Tea 1 & 1.8 \\
\hline Drops 2 & 0.06 & Tea 2 & 2.4 \\
\hline Drops 3 & 0.09 & Tea 3 & 2.5 \\
\hline Drops 4 & 0.09 & Tea 4 & 2.3 \\
\hline Drops 5 & 0.14 & Tea 5 & 2.1 \\
\hline Drops 6 & 0.18 & & \\
\hline
\end{tabular}

highest during bud formation and the lowest during ripeness [12]. It is further reported that a water-deficit led to a reduction in leaf-size combined with a higher ratio of oil glands, consequently resulting in an increased essential oil formation [26]. Therefore,
Perry et al. extracted $1.1 \%$ essential oil from dried $S$. officinalis ssp. major leaves, harvested while the plants were blooming [19]. Langa et al. determined $1.6 \%$ to $1.9 \%$ essential oil in S. lavandulifolia from Spain by applying the same CE extraction conditions. A favourable combination of different influencing factors perhaps promoted the relatively high oil yield in the investigated sage leaves [13].

With regard to the terpene composition, the economically important S. officinalis species showed a similar distribution (Fig. 6). In accordance with the literature, the characteristic terpenes were $\alpha$-pinene, $\beta$-pinene, camphene, 1,8-cineole, $\alpha$-thujone, $\beta$ thujone, camphor, borneol, $\alpha$-caryophyllene, and $\beta$-caryophyllene [12, 20, 27, 28].

For these, the highest $\alpha$-thujone yields were observed for S. officinalis and the Extrakta variety, while the lowest $\alpha$-thujone yields were detected in the essential oils of $S$. officinalis ssp. major, S. officinalis "Berggarten", and S. officinalis "Aurea". In addition, the comparably high camphor contents were characteristic for $S$. officinalis ssp. major and $S$. officinalis "Berggarten". On the other hand, the $S$. officinalis ssp. minor "Alba" clearly contained more $\beta$-caryophyllene than the other $S$. officinalis subspecies. S. officinalis "Aurea" could also be distinguished from the other $S$. officinalis samples by 


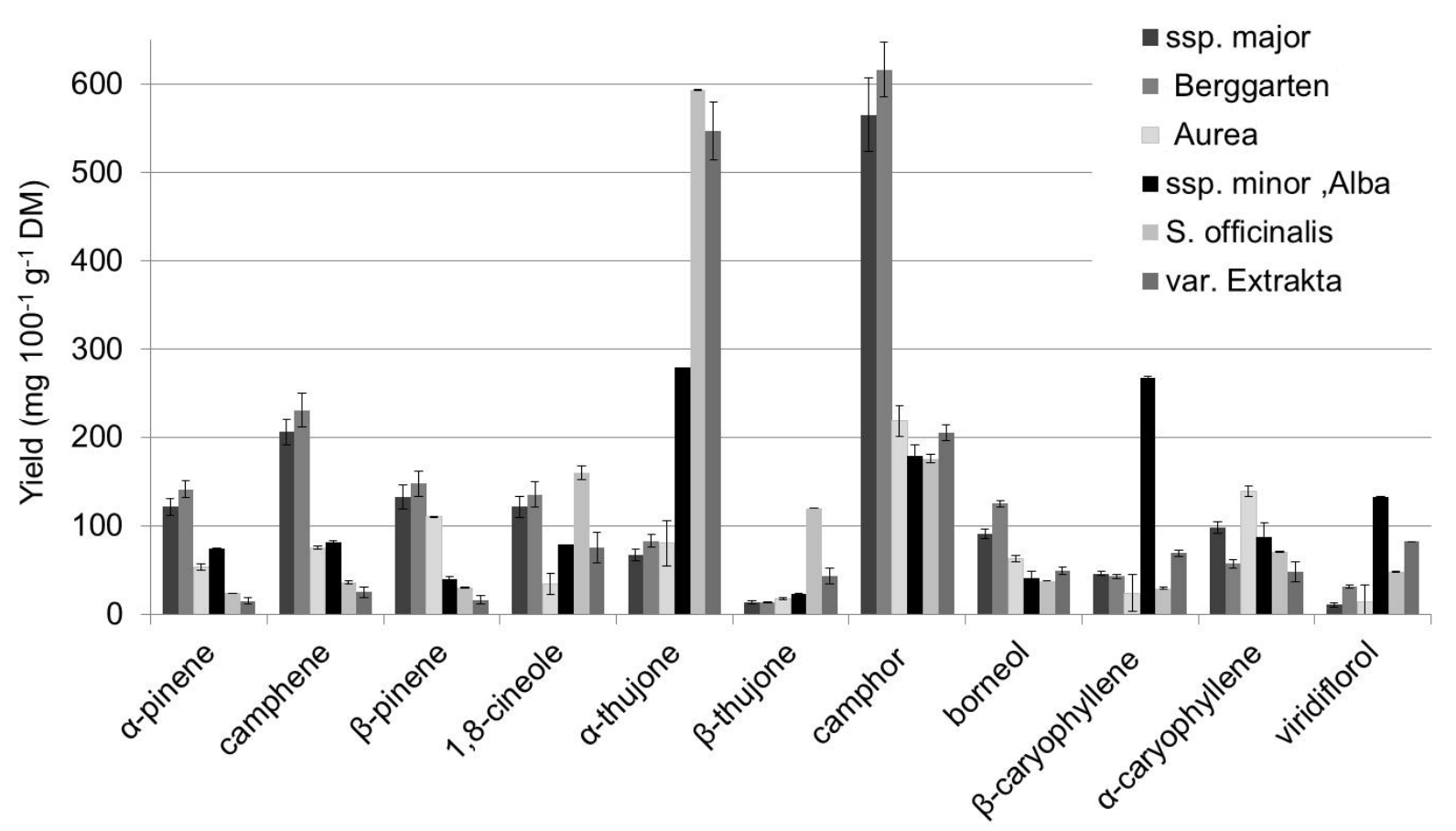

Fig. 6 Terpene composition of the $S$. officinalis species and subspecies (mean \pm SD).

its numerous sesquiterpenes. Hence, its terpene profile was rather comparable to the ornamental species such as S. madrensis, S. elegans, and $S$. barrelieri (Table. 3). S. lavandulifolia formerly considered as a subspecies of S. officinalis, showed great similarities to the $S$. officinalis species. Nevertheless, it was distinctive that camphor represented $50 \%$ of the total terpene content and that no thujone could be detected in S. lavandulifolia, which was in accordance with the findings by Savelev et al. [29]. However, other authors reported low quantities of thujone [13,30,31], which was probably due to a variety of influencing factors such as climatic stress. Characteristic for the S. sclarea leaves was the high ratio of germacrene D. These findings had previously been reported by Carrubba et al. [32]. However, it should be noted that, usually, the flowers rather than the leaves, of S. sclarea are used by the perfume industry [27]. Conspicuous was also the terpene profile of the species S. patens, which differed greatly from the remaining Salvia species, particularly in reference to its high $\delta$-selinene and $\gamma$-elemene yields.
Due to the remarkably low oil yields from $S$. coccinea, S. farinacea, and S. splendens, the terpene profiles could not be examined.

\subsection{Sage Teas}

The essential oil yields determined ranged from 1.8 to $2.1 \mathrm{~mL} 100^{-1} \mathrm{~g}^{-1}$ of tea, which was in the range of the investigated $S$. officinalis species and subspecies (1.5 to $2.6 \mathrm{mg} 100^{-1} \mathrm{~g}^{-1} \mathrm{DM}$ ). According to the manufacturer information, the sage teas were gotten from S. officinalis whereas Tea 5 was specified as an Extrakta variety. The terpene distribution obtained, especially the high $\alpha$-thujone and the comparably low camphor content, confirmed that Tea 5 was gained from S. officinalis var. Extrakta (Fig. 7). The remaining teas revealed high $\alpha$-thujone as well as high camphor yields. Hence, it was very likely that they had been obtained from mixed cultivars of e.g., $S$. officinalis and its subspecies major or "Berggarten". S. officinalis ssp. minor was excluded as botanical origin of the teas since the $\beta$-caryophyllene concentration determined was low, constantly. S. officinalis "Aurea" was also excluded due to its low $\alpha$-thujone content. 
Table 3 Chemical composition of Salvia essential oils, yields were estimated by means of GC/FID analysis.

\begin{tabular}{|c|c|c|c|c|c|c|c|c|c|c|c|c|}
\hline $\begin{array}{l}\text { Compounds (listed } \\
\text { according to retention } \\
\text { time) }\end{array}$ & $\begin{array}{l}\text { S. } \\
\text { officinalis }\end{array}$ & $\begin{array}{l}\text { S. off. } \\
\text { ssp. } \\
\text { major }\end{array}$ & $\begin{array}{l}\text { S. off. } \\
\text { ssp. } \\
\text { minor }\end{array}$ & $\begin{array}{l}\text { S. off. } \\
\text { "Aurea" }\end{array}$ & $\begin{array}{l}\text { S. off. } \\
\text { "Berggarten" }\end{array}$ & $\begin{array}{l}\text { S. off. var. } \\
\text { Extrakta }\end{array}$ & $\begin{array}{l}\text { S. } \\
\text { barrelieri }\end{array}$ & S. lavandulifolia & $\begin{array}{l}\text { S. } \\
\text { madrensis }\end{array}$ & $\begin{array}{l}S . \\
\text { patens }\end{array}$ & $\begin{array}{l}\text { S. } \\
\text { sclarea }\end{array}$ & $\begin{array}{l}\text { S. } \\
\text { elegans }\end{array}$ \\
\hline Tricyclene & + & + & + & + & + & + & + & + & + & & & \\
\hline$\alpha$-Thujene & + & + & + & + & + & + & + & + & + & + & & + \\
\hline$\alpha$-Pinene & + & +++ & ++ & ++ & +++ & + & + & ++++ & ++ & + & & + \\
\hline Camphen & + & ++++ & ++ & ++ & ++++ & + & + & +++ & + & + & & + \\
\hline$\beta$-Phellandrene & + & + & + & & + & + & & + & & & & \\
\hline$\beta$-Pinene & + & +++ & + & +++ & +++ & + & ++ & ++ & + & + & & \\
\hline$\beta$-Myrcen & + & + & + & + & + & + & + & ++ & + & & & \\
\hline$\alpha$-Terpinene & + & + & + & + & + & + & + & + & & & & \\
\hline Limonene & + & + & + & + & + & + & + & ++ & + & + & & \\
\hline trans- $\beta$-Ocimene & & & + & & & + & & ++ & + & & & \\
\hline Cymene & + & + & & + & + & & + & + & + & + & & \\
\hline 1,8-Cineole & +++ & +++ & ++ & + & +++ & ++ & + & ++++ & + & + & & \\
\hline cis- $\beta$-Ocimene & & & + & & + & & + & + & + & + & & + \\
\hline$\gamma$-Terpinene & + & + & + & + & + & + & + & + & + & & & \\
\hline allo-Ocimene & + & + & & & & & & + & & + & & \\
\hline Linalool & + & & + & & + & + & & + & & + & & + \\
\hline$\alpha$-Thujone & ++++ & ++ & ++++ & ++ & ++ & ++++ & ++ & & & + & & \\
\hline$\beta$-Thujone & +++ & + & + & + & + & + & + & & & & & \\
\hline Pinocarveol & & & & & & & & & & + & & \\
\hline Camphor & +++ & ++++ & +++ & ++++ & ++++ & ++++ & ++ & ++++ & & & & \\
\hline 4-Terpineol & + & & & + & + & & + & + & & & & \\
\hline 3-Pinanone & & & & & & & & & & + & & \\
\hline Borneol & + & ++ & + & ++ & +++ & + & + & +++ & & & & \\
\hline$\alpha$-Terpineol & & & & & & & & & & + & & \\
\hline Bornylacetate & + & + & + & + & ++ & + & + & + & +++ & & & \\
\hline$\delta$-Elemene & & & & & & & & & & + & & \\
\hline$\alpha$-Cubebene & & & + & + & & & + & & & & & \\
\hline Copaene & & & + & + & & & + & & + & + & + & \\
\hline$\beta$-Bourbonene & & & & & & & & & & + & & \\
\hline$\beta$-Elemene & & & & & & & & & & + & & \\
\hline$\delta$-Selinene & & & & + & & & + & & & + & & \\
\hline$\beta$-Caryophyllene & + & + & ++++ & + & + & ++ & + & ++ & ++++ & + & ++ & ++ \\
\hline Aromadendrene & + & + & & + & & & + & & + & & & \\
\hline$\alpha$-Caryophyllene & ++ & ++ & ++ & +++ & ++ & + & +++ & + & + & + & & + \\
\hline$\gamma$-Muurolene & & + & + & + & + & & + & & + & & & \\
\hline$(+)$-Ledene & + & + & + & + & + & + & + & & & & & + \\
\hline Germacrene D & & + & + & + & + & & + & + & + & + & +++ & + \\
\hline$\alpha$-Selinene & & & & + & & & & & + & & & \\
\hline$\gamma$-Elemene & & + & & + & + & & & & & + & + & + \\
\hline$\gamma$-Cadinene & + & + & + & + & + & & + & & & & & + \\
\hline$\delta$-Cadinene & & + & + & + & + & & + & & + & + & + & + \\
\hline Germacrene D -4-ol & & & & & & & & & & + & & \\
\hline Spathulenol & + & + & & + & + & & + & + & + & + & & + \\
\hline Viridiflorol & + & ++ & +++ & + & + & ++ & + & + & + & + & + & + \\
\hline Caryophyllene oxide & & + & + & + & & + & & & ++ & & & + \\
\hline
\end{tabular}

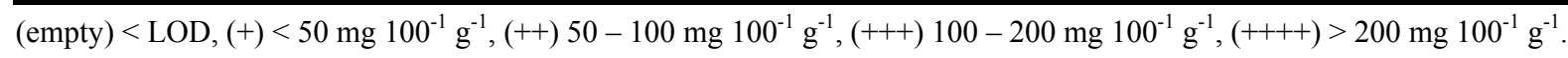




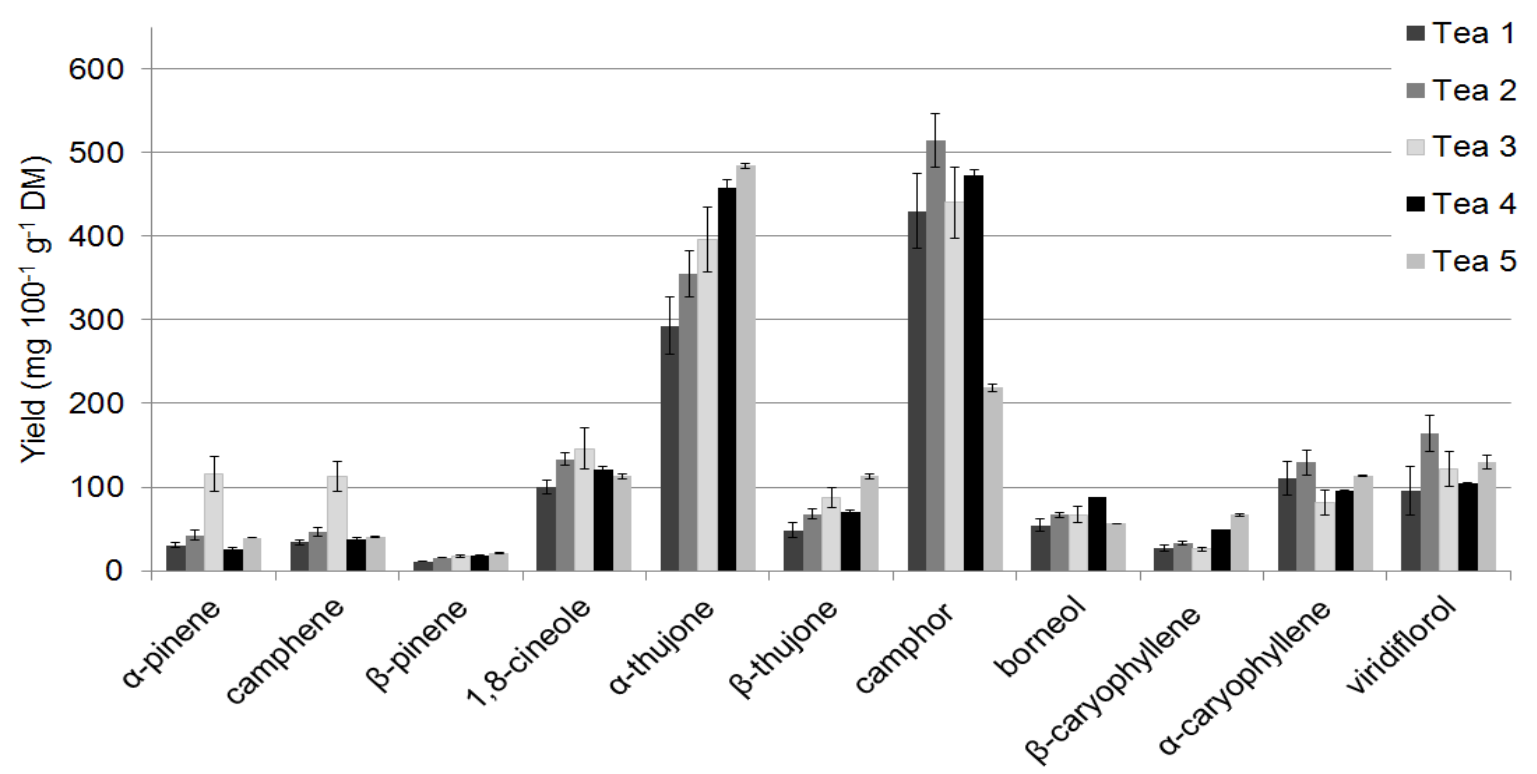

Fig. 7 Terpene composition of the sage teas (mean \pm SD).

\subsection{Sage Drops}

The sage oil declared on the drop-package ranged from $0.1 \%$ to $0.2 \%$ and the sage extract from $1.3 \%$ to $2.0 \%$. However, the experimentally determined oil contents were partly lower than expected. For this, a thermal degradation during steam distillation could be excluded (Fig. 5). For the drop-production, on the other hand, the essential oil was added at $120^{\circ} \mathrm{C}$ and the mixture subsequently cooled to $85{ }^{\circ} \mathrm{C}$ within 20 sec. Therefore, it can be assumed that there might be a thermal degradation during the production of hard caramels.

The comparison of the terpene compositions resulted in a very similar pattern among the sage drops examined (Fig. 8). The manufacturer information was only available for Drops 1 , where the essential oil of S. officinalis was used. However, the determined ratio of $\alpha$-thujone to camphor was in contrast to $S$. officinalis and rather comparable to $S$. officinalis ssp. major. The drops as well as the subspecies exhibited low $\alpha$-thujone and high camphor contents. Therefore, the essential oil of $S$. officinalis ssp. major was possibly used for the production of sage drops.

\subsection{Toxicological Aspects}

Due to its acute toxicity, especially the $\alpha$-thujone content is of relevance. However, in the EC Flavoring Regulation (No.1334/2008-EFFA, valid since 01/20/2011) which controls thujone-containing drinks due to the acute toxicity of $\alpha$-thujone $\left(\mathrm{LD}_{50}\right.$ rat, oral: $90 \mathrm{mg} \mathrm{kg}{ }^{-1} \mathrm{BW}$ ), neither a maximum quantity is declared for food products nor does the regulation apply to dried plants and sage tea as they are considered medications. Among the commercially used Salvia species, the highest $\alpha$-thujone yields were detected in S. officinalis and its Extrakta variety (Table. 4). Interestingly, no thujone was determined in the essential oil of $S$. lavandulifolia. Therefore, $S$. lavandulifolia, but also $S$. officinalis ssp. major and "Berggarten", are particularly suitable for medicinal teas or food applications due to their high oil yields combined with the medium $\alpha$-thujone contents.

The German Federal Institute for Risk Assessment (BfR) indicates a TMDI (temporary maximum daily intake) of $0.01 \mathrm{mg}$ thujone $\mathrm{kg}^{-1} \mathrm{BW}$ (body weight) per day. With regard to the investigated sage drops, $2 \mathrm{mg}$ to $8 \mathrm{mg}$ thujone per package $(50 \mathrm{~g})$ were determined. According to the suggested TMDI, children $(25 \mathrm{~kg}$ BW) and adults (75 kg BW) should not exceed a daily 


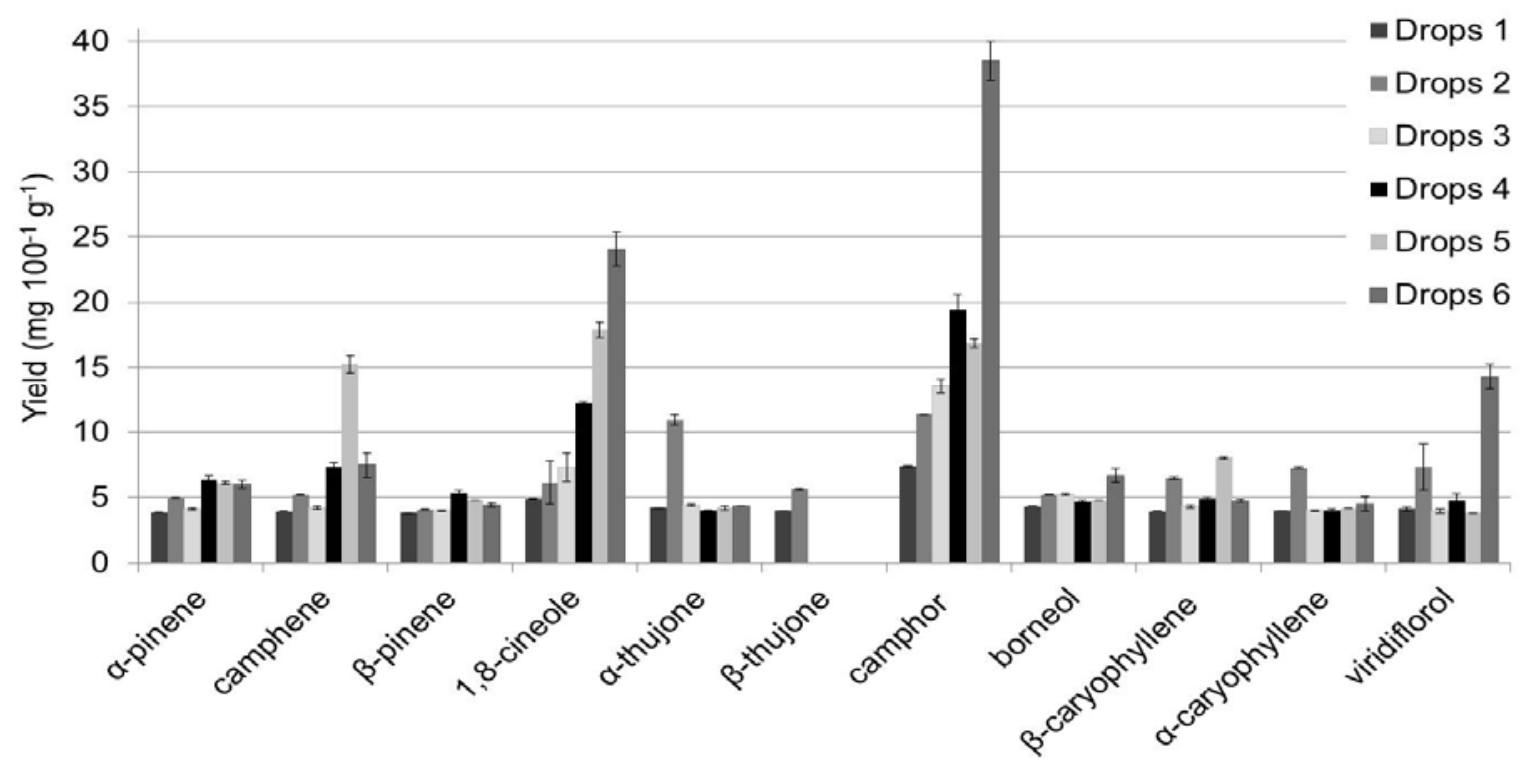

Fig. 8 Terpene composition of the sage drops (mean \pm SD).

Table 4 Determined $\alpha$-thujone and $\beta$-thujone yields.

\begin{tabular}{lccc}
\hline Salviaspecies & $\alpha$-Thujone & $\begin{array}{c}\beta \text {-Thujone } \\
\left(\mathrm{mg} \mathrm{100} \mathrm{g}^{-1}\right.\end{array}$ & $\begin{array}{c}\text { Total } \\
\text { thujone }\end{array}$ \\
\hline S. officinalis & 593.7 & 119.9 & 713.6 \\
S. off. var. Extrakta & 547.2 & 43.3 & 590.5 \\
S. off. ssp. minor “Alba” & 279.2 & 23.5 & 302.7 \\
S. off. "Aurea” & 80.2 & 18.0 & 98.2 \\
S. off. "Berggarten” & 83.0 & 13.7 & 96.7 \\
S. off. ssp. major & 66.8 & 13.5 & 80.3 \\
S. sclarea & $<$ LOD & $<$ LOD & - \\
S. lavandulifolia & $<$ LOD & $<$ LOD & - \\
Sage teas & $293.0-484.3$ & $48.4-113.1$ & $314.4-597.4$ \\
Sage drops & $4.0-10.9$ & $0.0-5.6$ & $4.0-16.5$ \\
\hline
\end{tabular}

${ }^{1}$ yield (mg $100^{-1} \mathrm{~g}^{-1}$ drops), LOD limit of detection.

intake of $0.25 \mathrm{mg}$ and $0.75 \mathrm{mg}$ thujone. Hence, children should only consume $1.6 \mathrm{~g}$ (1-2 drops) and adults only $4.7 \mathrm{~g}$ (2-3 drops) of the sage drops containing $8 \mathrm{mg}$ thujone per $50 \mathrm{~g}$ package. According to this, toxicological effects are not expected with moderate consumption. Caution should be exercised with the correct dosage of loose sage tea.

\section{Conclusions}

In conclusion, it could be demonstrated that steam distillation in terms of the Moritz-Apparatus and the Clevenger-Extraction were equally applicable for the extraction of the essential sage oil in low sample amounts of up to $3 \mathrm{~g}$. However, the ultrasonic extraction of the essential oil appeared to be a promising time-saving alternative. According to the acquired terpene profiles, the investigated Salvia species could be differentiated from each other. To some extent, it was even possible to correlate the terpene distribution of the teas and drops with the botanical origin of the processed sage oil.

\section{Acknowledgments}

Sincere thanks to the Botanical Garden of Dresden and Mrs. B. Schoen from the Saxon State Office of Environment, Agriculture, and Geology for providing the sage plants.

\section{References}

[1] H. Ögütçü, A. Sökmen, M. Sökmen, M. Polissiou, J. Serkedjieva, D. Daferera, et al., Bioactivities of the various extracts and essential oils of Salvia limbata C.A. Mey and Salvia sclarea L., Turk J. Biol. 32 (2008) 181-192.

[2] L. Jirovetz, G. Buchbauer, Z. Denkova, A. Slavchev, A. Stoyanova, E. Schmidt, Chemical composition, antimicrobial activities and odor descriptions of various Salvia sp. and Thuja sp. essential oils, Nutrition 90 (2006) 152-159.

[3] L. Jirovetz, K. Wicek, G. Buchbauer, V. Gochev, T. 
Girova, A. Stoyanova, et al., Antifungal activities of essential oils of Salvia lavandulifolia, Salvia officinalis and Salvia sclarea against various pathogenic Candida species, J. Essent. Oil-Bear Plants 10 (2007) 430-439.

[4] M.D.L. Moretti, A.T. Peana, M. Satta, A study on anti-inflammatory and peripheral analgesic action of Salvia sclarea oil and its main components, J. Essent. Oil Res. 9 (1997) 199-204.

[5] R. Hänsel, K. Keller, H. Rimpler, G. Schneider, Hagers Handbuch der pharmazeutischen Praxis, 5. Auflage, Hrsg. F. von Bruchhausen, Springer-Verlag, Berlin Heidelberg, 1994.

[6] T. Bönnhoff, Salbei-Salvia officinalis: Das Buch zur Heilpflanze des Jahres 2003, NHV Theophrastus, 2003.

[7] X.W. Li, I.C. Hedge, Lamiaceae (Labiatae), Flora of China 17, pp. 195-222.

[8] S. Glisic, J. Ivanovica, M. Ristic, D. Skala, Extraction of sage (Salvia officinalis L.) by supercritical $\mathrm{CO}_{2}$ : Kinetic data, chemical composition and selectivity of diterpenes, J. of Supercritical Fluids 52 (1994) 62-70.

[9] M. Adam, P. Dobiáś, P. Pavlíková, K. Karel Ventura, Comparison of solid-phase and single-drop microextractions for headspace analysis of herbal essential oils, Cent. Eur. J. Chem. 7 (3) (2009) 303-311.

[10] A.L. Dawidowicz, E. Rado, Matrix solid-phase dispersion (MSPD) in chromatographic analysis of essential oils in herbs, J. Pharm. Biomed. Anal. 52 (2010) 79-85.

[11] O.A. Onayade, J.J.C. Scheffer, A. Baerheim Svendsen, Polynuclear aromatic compounds and other constituents of the herb essential oil of Salvia coccinea Juss. Ex Murr., Flavour Fragrance J. 6 (1991) 281-289.

[12] M.H. Mirjalili, P. Salehi, A. Sonboli, M.M. Vala, Essential oil variation of Salvia officinalis aerial parts during its phenological cycle, Chem. Nat. Compd. 42 (1) (2006) 19-23.

[13] E. Langa, G. Della Porta, A.M.F. Palavra, J.S. Urieta, A.M. Mainar, Supercritical fluid extraction of Spanish sage essential oil: Optimization of the process parameters and modeling, J. of Supercritical Fluids 49 (2009) 174-181.

[14] M.B. Taarit, K. Msaada, K. Hosni, B. Marzouk, Changes in fatty acid and essential oil composition of sage (Salvia officinalis L.) leaves under $\mathrm{NaCl}$ stress, Food Chem. 119 (2010) 951-956.

[15] European Pharmacopoeia, 6th ed., 8. edition (Ph. Eur. 6.8), Deutscher Apotheker Verlag, 2010.

[16] German Pharmacopoeia, 10th ed., 3ed ed., Govi-Verlag, 1994.

[17] A. Carrubba, R. la Torre, R. Piccaglia, M. Marotti, Characterization of an Italian biotype of clary sage (Salvia sclarea L.) grown in a semi-arid Mediterranean environment, Flavour Fragrance J. 17 (2002) 191-194.

[18] Ł. Kuźma, D. Kalemba, M. Różalski, B. Różalska, M. Więckowska-Szakiel, U. Krajewska, et al., Chemical composition and biological activities of essential oil from
Salvia sclarea plants regenerated in vitro, Molecules 14 (2009) 1438-1447.

[19] N.B. Perry, R.E. Anderson, N.J. Brennan, M.H. Douglas, A.J. Heaney, J.A. Mc Gimpsey, et al., Essential oils from Dalmatian Sage (Salvia officinalis L.): Variations among individuals, plant parts, seasons, and sites, J. Agric. Food Chem. 47 (1999) 2048-2054.

[20] B. Bozin, N. Mimica-Dukic, I. Samojlik, E. Jovin, Antimicrobial and antioxidant properties of rosemary and sage (Rosmarinus officinalis L. and Salvia officinalis L., Lamiaceae) essential oils, J. Agric. Food Chem. 55 (2007) 7879-7885.

[21] T. Aşkun, K. Hüsnü Can Başer, G. Tümen, M. Kürkçüoğlu, Characterization of essential oils of some Salvia species and their antimycobacterial activities, Turk. J. Biol. 34 (2010) 89-95.

[22] D. Kustrak, Kreuzsalbei-Salvia officinalis L. subspecies minor f. auriculata, Pharm. Acta. Helv. 63 (1988) 254-256.

[23] L. De Martino, G. Roscigno, E. Mancini, E. De Falco, V. De Feo, Chemical composition and antigerminative activity of the essential oils from five Salvia species, Molecules 15 (2010) 735-746.

[24] F.S. Sharopov, W.N. Setzer, The essential oils of Salvia sclarea L. from Tajikistan, Rec. Nat. Prod. 6 (1) (2012) 75-79.

[25] M. Strzalka, D. Chwedoruk, L. Halas, Z. Janeczko, Chemical composition of essential oils found in selected Salvia species, SOFW Journal 137 (8) (2011) 18-29.

[26] I. Bettaieb, N. Zakhama, W. AidiWannes, M.E. Kchouk, B. Marzouk, Water deficit effects on Salvia officinalis fatty acids and essential oils composition, Sci. Hortic. 120 (2009) 271-275.

[27] G. Bernotienè, O. Nivinskienè, R. Butkienè, D. Mockute, Essential oil composition variability in sage (Salvia officinalis L.), Chemija 18 (4) (2007) 38-43.

[28] A.T. Peana, M.D.L. Moretti, C. Juliano, Chemical composition and antimicrobial action of the essential oils of Salvia desoleana and S. sclarea, Planta Medica 65 (1999) 752-754.

[29] S.U. Savelev, E.J. Okello, E.K. Perry, Butyryl and acetyl-cholinesterase inhibitory activities in essential oils of Salvia species and their constituents, Phytotherapy Research 18 (2004) 315-324.

[30] M.D. Guillén, N. Cabo, J. Burillo, Characterization of the essential oils of some cultivated aromatic plants of industrial interest, J. Agric. Food Chem. 70 (1996) 359-363.

[31] N.S.L. Perry, P.J. Houghton, P. Jenner, A. Keith, E.K. Perry, Salvia lavandulifolia essential oil inhibits cholinesterase in vivo, Phytomedicine 9 (2002) 48-51.

[32] C. Schmiderer, P. Grassi, J. Novak, M. Weber, C. Franz, Diversity of essential oil glands of clary sage (Salvia sclarea L., Lamiaceae), Plant Biol. 18 (2008) 433-440. 